\title{
FUTEBOL, O ESPETÁCULO MUNDIAL* RESENHA DA OBRA FUTEBOL E GLOBALIZAÇÃO
}

\author{
GRAD. NATASHA SANTOS \\ Graduação em Educação Física pela Universidade Positivo (UP) e Mestranda em História pela \\ Universidade Federal do Paraná (UFPR) (Paraná - Brasil) \\ E-mail: nata.shas@ig.com.br
}

\section{DR. ANDRÉ MENDES CAPRARO}

Doutor em História pela UFPR e Professor Adjunto do Departamento de Educação Física da UFPR

(Paraná - Brasil)

E-mail: andrecapraro@onda.com.br

\section{GRAD. JACKSON FERNANDO MOSKO}

Graduação em Educação Física pela UP e Membro do Núcleo de Estudos Futebol e Sociedade

(Paraná - Brasil)

E-mail: jackson_mosko@hotmail.com

\section{GRAD. RIQUELDI STRAUB LISE}

Graduação em Educação Física pela UP e Membro do Núcleo de Estudos Futebol e Sociedade

(Paraná - Brasil)

E-mail: ricklise@ig.com.br

* O presente trabalho não contou com apoio financeiro de nenhuma natureza para sua realização. Embora um dos autores desta resenha seja também autor de um dos capítulos da obra analisada, não houve conflito de interesses para a realização do presente estudo. O pesquisador em questão, na condição de orientador dos demais autores da resenha, foi responsável apenas pela supervisão destes quanto à construção do texto, ou seja, não interferiu no conteúdo explicitado, atendo-se, exclusivamente, aos procedimentos metodológicos necessários. Além disso, em relação à obra resenhada, não existiu qualquer tipo de participação por parte do referido pesquisador na seleção dos autores e temáticas, tampouco no conteúdo exposto nos demais textos, tendo sido ele responsável apenas pela produção de um dos I I artigos que compõem o livro. 
O livro Futebol e globalização, organizado por Luiz Carlos Ribeiro - cuja área de pesquisa envolve, também, o estudo da história social dos esportes -, corresponde a uma coletânea de trabalhos realizados em torno da análise do futebol e sua relação com a globalização. A obra é dividida em onze capítulos, por meio dos quais cada autor aborda uma temática específica do futebol, com importantes questionamentos sobre os efeitos ocasionados pela globalização, bem como suas implicações nos âmbitos esportivo e social. Essa internacionalização, vinculada à expansão capitalista, é discutida a partir de modelos europeus e latino-americanos, colocando em xeque as concepções estabelecidas, até então, acerca do esporte em foco.

A coletânea se fragmenta em três seções, a fim de tratar dos diferentes aspectos no que concerne à globalização do futebol. A primeira delas é $O$ futebol no mercado globalizado, composta por cinco capítulos, carregados de uma abordagem empírica acerca do crescimento e da internacionalização do mercado esportivo (futebolístico). Tomando por base alguns dados veiculados em jornais e revistas durante a Copa do Mundo de 2006, realizada na Alemanha, Antonio Jorge Soares e colaboradores analisam a deterioração da "identidade nacional" em razão da naturalização e da dupla cidadania de jogadores, bem como a consequente perda do sentido de competição entre nações. Essa mercantilização do futebol e absorção do mercado financeiro desse evento - que movimenta bilhões de dólares e mobiliza nações no mundo inteiro -, transforma-no em um grande e lucrativo negócio. Como supracitado, essa espetacularização do futebol, que aparece com investimentos financeiros exorbitantes, principalmente por parte da mídia televisiva, remete à ideia das implicações relacionadas com a violência e com a construção de uma identidade, aprofundando-se em um padrão masculino de socialização. Essa criação de uma identidade masculina pode estar associada ao trabalho e ao futebol por mobilizar seu corpo e alma. Bem como a profissionalização do futebol, que excluiu o sentido de honra e lealdade presentes anteriormente, podendo ser umas das questões para a violência vivenciada na sociedade, assim como a precarização das condições de trabalho induzidas pelo capitalismo.

Nesse sentido, o futebol é, inevitavelmente, influenciado por um consumo em grande escala - interesse lucrativo -, sendo assim redimensionado para a espetacularização e, utilizando-se da expressão de Luiz Ribeiro, para um processo de "aburguesamento", o que desperta preocupação na reestruturação de suas políticas públicas.

A organização do futebol profissional está fundamentada nessa transformação dos clubes em empresas, como destacado por Marcelo Proni e Felipe Zaia, três clubes europeus - Manchester United, Milan e Real Madrid - e suas diferentes 
estratégias de arrecadação de divisas, entre as principais: os direitos de transmissão de jogos, comerciais e patrocínios, a renda adquirida com a venda de ingressos e os produtos licenciados do clube envolvendo o dia do jogo. Dessa forma, ocasiona-se uma concorrência na busca de recursos financeiros cada vez mais rentáveis, a fim de satisfazer o público consumidor e, obviamente, aumentar os lucros do clube. Em se tratando do futebol brasileiro, é inquestionável a necessidade dos clubes em profissionalizar suas administrações, para uma maior participação nos lucros envolvidos com esta atividade, assim como ocorre com equipes europeias. Desse modo, José Mosko se utiliza de alguns conceitos, formulados por Pierre Bourdieu para embasar e apresentar as estratégias utilizadas pelo Clube Atlético Paranaense, no intuito de garantir a manutenção de sua existência e melhorar sua posição no cenário do futebol brasileiro.

Embora o Estado tente a intervir - a fim de controlar o esporte -, o futebol, junto ao capitalismo e às evoluções tecnológicas, tornou-se um mercado responsável por profundas transformações, dentre as quais está a gradativa exclusão da classe trabalhadora dos estádios. De acordo com Fernando Mezzadri, isso se dá, primeiramente, em razão de questões financeiras, uma vez que o interesse dos clubes não abrange torcedores fanáticos, mas "clientes" com um poder aquisitivo considerável. Os maiores exemplos dessas estratégias financeiras se concentram nos clubes europeus - maior mercado de jogadores da atualidade.

Na segunda seção, por sua vez - Da teoria à historiografia - há a elaboração de um debate que abrange a globalização, a violência e a historiografia do futebol na América Latina. Aqui, Wanderley Marchi Júnior e Gilmar Afonso destacam o esporte como uma atividade em constante desenvolvimento e definida por uma determinada cultura social; ao passo que a globalização aparece como um processo de redefinição das fronteiras geopolíticas e de troca de manifestações culturais que, inevitavelmente, levam à um consumo em grande escala. Nesse sentido, o esporte, também influenciado por este processo, tem sido redimensionado para a espetacularização e, assim, desperta preocupação na reestruturação de suas políticas públicas.

Segue-se com Pedro Bodê de Moraes que relaciona o fator globalização à violência praticada por torcedores, bem como sua relação com a construção da identidade e do trabalho, a partir da historiografia do futebol na América Latina. Outro ponto importante é o distanciamento da forma amadora de praticar o futebol e, consequentemente, da civilidade, bem expressa pelos preceitos de fair play, que correspondiam ao autocontrole indispensável às condutas sociais. Em outras palavras, o crescimento econômico futebolístico, foco de toda esta discussão, está diretamente relacionado à violência urbana e à segurança pública, uma vez que as 
tensões estão presentes dentro e fora dos estádios, não se tratando apenas de um hooliganismo, mas da violência em geral, que exige intervenção Estatal. No âmbito europeu, os clubes mais estruturados passaram a administrar suas divisas como empresas, supervisionadas pela UEFA - organização que comanda o futebol no continente - a fim de evitar essas possíveis tensões.

Embora o esporte, via de regra, apresente determinada relevância histórica na vida diária da população, bem como na economia, na política ou na cultura, apenas nos últimos 10 anos é que se consolidou como um objeto de estudo, nas ciências sociais latino-americanas. É a partir daí que Pablo Alabarces recupera algumas reflexões, oriundas de outras obras, essenciais ao debate; e a partir da pesquisa sócio-histórica argentina e latino-americana, traça um mapa das investigações sobre o futebol. Esses incipientes estudos reiteram que o futebol, há muito tempo, deixou de limitar-se a uma prática esportiva ou a um entretenimento: é um espetáculo que abrange importância econômica e política, sendo um dos mecanismos de mobilidade social mais eficaz dos dias atuais. Além disso, o pesquisador alemão Stefan Rinke enfatiza o futebol, na América Latina, como recurso de identidade, do mesmo modo com que as obras literárias ou culturais identificam nações ou continentes.

Por fim, tem-se a seção intitulada A Experiência Histórica, que expõe duas diferentes "experiências históricas", no que se refere ao processo de internacionalização do futebol no Brasil. No Brasil, com o governo Vargas - desde a década de 1940 -, que visava à criação de uma identidade nacional, de um patriotismo exacerbado vinculado à prática dos esportes, em especial o futebol, pode-se observar a grande expansão na quantidade de estádios construídos. Tudo isso com o intuito do Estado, por meio de governos municipais e estaduais, manter as ações do governo o mais próximo possível do futebol, utilizando-o como arma política - e por que não dizer, alienante.

Já na metade da década de 1950, o país, sob o comando do presidente Juscelino Kubitschek (JK) cujo lema era cinquenta anos de desenvolvimento em cinco de governo, buscava uma modernização mais intensa, refletida no futebol - com a reformulação da CBD liderada por João Havelange. É aí que se destacam os primeiros indícios da mercantilização do futebol no Brasil, conforme o questionamento realizado pela crônica na época sobre a venda dos campeões mundiais (1958), e suas implicações no contexto social, já que os jogadores eram considerados símbolos vitoriosos que honraram a pátria. Nesse sentido, Miguel de Freitas busca verificar a resposta do futebol às tentativas de modernização no Brasil, implementadas por JK na década de 1950, por meio da análise de uma 
divergência entre Jornais Esportivos respeitadíssimos e os dirigentes de clubes de futebol brasileiros.

Quanto às crônicas esportivas, é interessante destacar que estas - bem como os cronistas -, também sofreram a influência da modernização do esporte, isto é, os cronistas se tornaram celebridades, podendo-se afirmar que a própria crônica passou por um processo de espetacularização. Um exemplo notório e indispensável, utilizado por André Capraro, é a figura de Armando Nogueira que trata o esporte, em especial o futebol, com uma sutileza incomparável - com a capacidade de enaltecer o passado sem menosprezar o presente. Nogueira é um exemplo de sucesso que avançou em conjunto com a modernização da mídia e a espetacularização dos esportes, sem perder a essência e a beleza estética esta, muito valorizada pelo escritor. Apesar de esse posicionamento tê-lo levado a receber críticas de seu mestre e amigo Nelson Rodrigues - literato famoso e com inegável paixão pelo futebol -, Nogueira se beneficiou da arte de escrever e do avanço tecnológico, para relatar com maior elegância, a beleza realizada e recriada a cada jogo nos estádios.

Em síntese, dessa discussão atual e coerente, infere-se que a globalização tornou-se um elemento essencial aos clubes no que diz respeito à sobrevivência financeira - característica primordial do sistema capitalista. Entretanto, constata-se que algumas de suas características ofuscaram elementos ideológicos e estéticos presentes no esporte em outros momentos históricos. $\bigcirc$ futebol ainda é uma paixão nacional, porém, hoje, mais por ser um espetáculo global, atraente pelo show recriado pelas mídias; abandonando-se os "clichês" sobre o amor à camisa ou jogadas criativas, como as atribuídas ao jogador Garrincha, por exemplo. Os torcedores, apaixonados pelo esporte, aqueles que anos atrás derramariam lágrimas pelo time, pouco a pouco são substituídos por clientes - com a responsabilidade mensal do pagamento de taxas, a fim de manter seu lugar fixo na arquibancada.

No que se refere à obra em si, cabe evidenciar o fato de ser uma coletânea de artigos, de diferentes autorias. É improvável que um único autor desse conta, satisfatoriamente, de abordar a globalização no futebol sob perspectivas tão distintas, como as apresentadas ao longo dos I I capítulos. Nesse sentido, compreende-se o que pode ser uma "necessidade" de fragmentar o livro, para então unificá-lo posteriormente, tendo em vista que os textos dialogam entre si. Entretanto, esse diálogo "direto" só é possível na medida em que não extrapola a seção em que está inserido. Em outras palavras, constata-se uma consequência positiva que acarreta uma negativa: por um lado, tem-se especialistas tratando, com competência, de suas linhas de pesquisas; ao passo que, por outro, a obra 
fica definitivamente fragmentada em três capítulos (seções). Este método de publicação relativo à produção bibliográfica em Ciências Sociais e Humanas vem se acentuando nas últimas duas décadas. Consequentemente se faz necessária uma reflexão/debate no campo acadêmico em relação aos ganhos e perdas gerados ao adotar o formato "coletânea".

\section{REFERÊNCIA}

RIBEIRO, Luiz (Org.). Futebol e globalização. Jundiaí: Fontoura, 2007.

Recebido: II fev. 2009

Aprovado: $30 \mathrm{abr} .2010$

Endereço para correspondência:

Natasha Santos

Rua Manoel Ricardo de Oliveira, n. 48 - Bairro Sítio Cercado

Curitiba-PR

CEP: 81.920-550 